\title{
Study on Anti-seismic Collapse of Reinforced Concrete Frame Structures
}

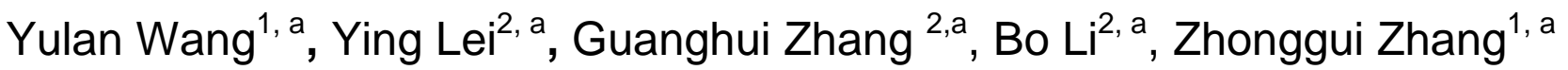 \\ ${ }^{1}$ Hubei University of Education, Wuhan, 430205,China \\ ${ }^{2}$ Wuhan University of Technology, Wuhan, 430070,China \\ amaggyw@sina.com
}

\begin{abstract}
Keywords: reinforced concrete frame structure, anti-seismic collapse, numerical simulation, seismic performance, incremental dynamic analysis method
\end{abstract}

Abstract: The frame structure of reinforced concrete is a kind of structural form with good seismic performance. But the strong earthquake damage show that the $\mathrm{RC}$ frame structure under the large earthquakes will also be seriously collapsed and destroyed. In the case of strong earthquake, the RC frame structure may have insufficient anti-seismic collapse ability. In China, the seismic design of building structure is usually depended on seismic design under minor earthquake. It lack sufficient research on the anti-collapse analysis of strong earthquake. In this paper, incremental dynamic analysis method is adopted. The RC frame structure in zones with seismic intensity VII $(0.15 \mathrm{~g})$ according to the Chinese Seismic Design Code is input seismic waves, the seismic response of the structure under frequent earthquake, rare earthquake and the huge earthquake was obtained and analyzed. The collapse mechanism of RC frame structure under huge earthquake is studied. The results can provide the references for anti-seismic collapse design of structure.

\section{Introduction}

Earthquakes is a devastating natural disasters. Because of its occurrence with sudden and unpredictable, large earthquakes can cause significant economic losses and casualties, and the collapse of building under the earthquake is one of the main causes of casualties. RC frame structure is one of the commonly used structural forms in China. The structure can be flexibly set space, force transmission route is clear, have sufficient strength, have good ductility and strong intergrity. However, in the previous major earthquakes, part of the RC frame structure also has suffered serious collapse damage. At present, China's anti-seismic design specifications of engineering structure is that No Collapsing with Strong Earthquake. But the anti-seismic collapse design of most buildings under rare earthquake is only based on the seismic conceptual design and details of seismic design, it lack specific anti-seismic collapse design and calculation, the anti-collapse research of RC frame structure is not perfect. In this paper, numerical simulation software is used to simulate the entire collapse process of RC frame structure under earthquake action, and the collapse mechanism and rule of RC frame structure under earthquake action are analyzed and studied.

\section{Incremental Dynamic Analysis (IDA)}

Icremental Dynamic Analysis is referred to as IDA method. The principle of the IDA method is that setting a series of monotonically increasing earthquake intensity indices for a given ground motion input, and elastic-plastic time history analysis of structure is executed for each earthquake intensity indices of the earthquake input. At last, a series of elastic-plastic seismic response of structures is obtained. Because IDA method is gradually increasing the intensity of the earthquake until the whole structure collapses, the method is very suitable for anti-seismic collapse performance analysis of the overall structure. The IDA method can reveal the seismic performance of the structure under the same earthquake with different intensity, and the seismic capacity of the structure is evaluated $^{[1,2]}$. 


\section{Establishment of Numerical Model}

In this paper, ANSYS/LS-DYNA is used to simulate the collapse process of 10-story RC frame structure under earthquake action. In the models, the beam elements are used to describe beams and columns, the plate elements are used to simulate floors. The plastic kinematic model are used to simulate concrete. The volume-weight of concrete is $24 \mathrm{kN} / \mathrm{m}^{3}$, the elasticity modulus of concrete is $3 \times 10^{4} \mathrm{MPa}$, the yield stress is $30 \mathrm{MPa}$, poisson's ratio is

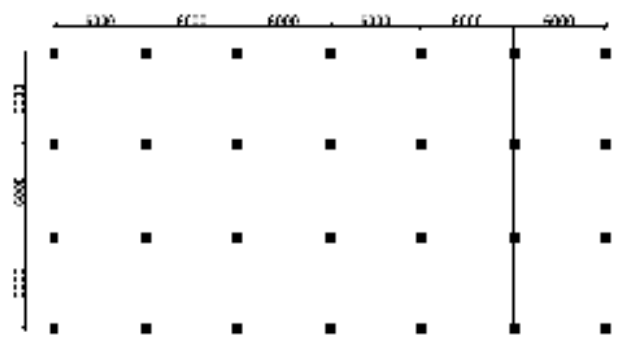

Fig. 1 The Plane Layou of Structure 0.25 , the failure strain is $0.63 \%$. The storey heigh of $\mathrm{RC}$ frame structure is $3.9 \mathrm{~m}$, the columns spacing of vertical and horizontal direction is $6 \mathrm{~m}$, the structure plane layout is shown in Figure 1. In the RC frame structure, the strength grade of beam, plate and column are $\mathrm{C} 30^{[3,4]}$.

\section{Modal Analysis}

The basic vibration characeristics of structure under free vibration is known as mode. The purpose of mode analysis is to calculate the inherent frequency and the vibration mode of the structure. The mode analysis is the main content of structure dynamical analysis, also is the basis of time history response analysis. In the paper, the first eight modes were extracted by modal analysis and the first eight frequency of structure are shown in Table 1, the first four vibration mode diagram are shown in Figure 2. the mode analysis shows that the first vibration mode is the overall translation motion along the longtudinal direction, the second vibration mode is the overall translation motion along the transverse, the third vibration mode is twist around the vertical, the seismic mode of the structure in lower order is the overall vibration.

Table 1 The Mode Parameters of Model

\begin{tabular}{cccc}
\hline Mode & Frequency(Hertz) & Mode & Frequency(Hertz) \\
\hline 1 & 0.76705 & 5 & 2.3708 \\
2 & 0.78129 & 6 & 2.5800 \\
3 & 0.84856 & 7 & 4.0391 \\
4 & 2.3342 & 8 & 4.0638 \\
\hline
\end{tabular}

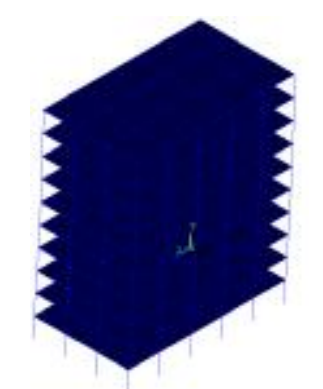

The First Vibration Mode

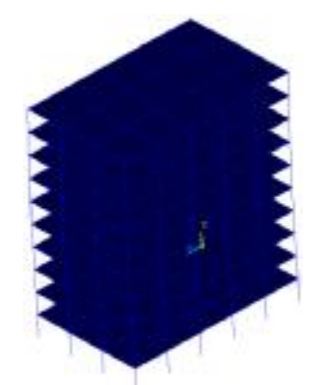

The Second Vibration Mode The Third Vibration Mode

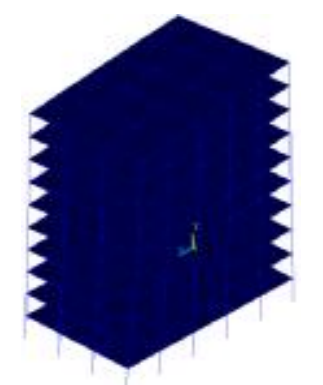

Fig. 2 The Vibration Shape Diagram of RC Frame Structure

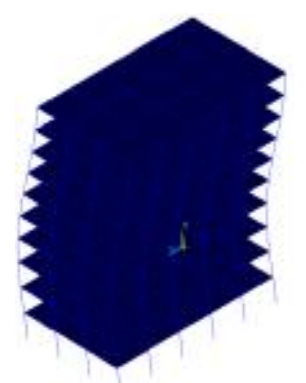

The Fourth Vibration Mode

\section{Time History Analysis}

In this paper, the incremental time history analysis method is used to carry out the anti-collaplse time-history analysis of structures under earthquake action. The anti-earthquake degree is VII $(0.15 \mathrm{~g})$, the site classification is class II. The Tianjin seismic waves are used for structural analysis, the duration of earthquake action is 20 seconds and the time interval of earthquake input is 0.02 seconds. The earthquake waves are only input along the $\mathrm{X}$ direction. The earthquake intensity were input to structure include frequent earthquake, rare earthquake and huge earthquake ${ }^{[5]}$. 
Interlayer Displacement Analysis. Because the structure columns along vertical height of structure is equal section, the bottom interlayer displacement of structure is the largest under earthquake action. Under the action of frequent earthquake and rare earthquake, the interlayer displacement time history curves of ground floor are shown in Fig. 3 and Fig. 4. The time history curves show that the maximum of the interlayer displacement time history curves of ground floor is $15 \mathrm{~mm}$ under frequent earthquake and the maximum of interlayer displacement time history curves of ground floor is $80 \mathrm{~mm}$ under rare earthquake, the interlayer displacement meet specification limits.

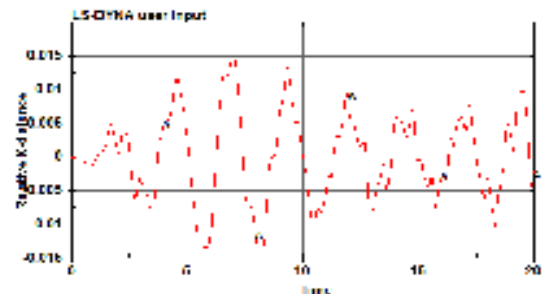

Fig. 3 Interlayer Displacement under Frequent Earthquake

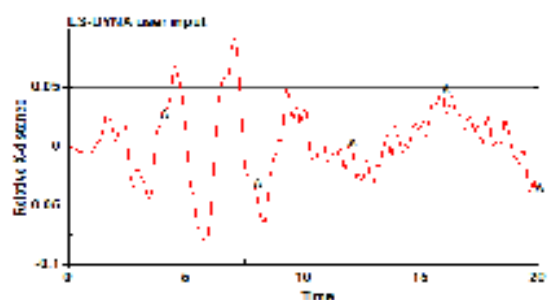

Fig. 4 Interlayer Displacement under Rare Earthquake

Analysis of Maximum Displacement of the Top. The time history curves of the top of structure under frequent earthquake and rare earthquake are shown Fig. 5 and Fig. 6. The maximum displacement of the top of structure is $70 \mathrm{~mm}$ under frequent earthquake. The maximum displacement of the top of structure is $400 \mathrm{~mm}$ under rare earthquake. The the maximum displacement of top of structure is more strongly than bottom displacement of the structure.

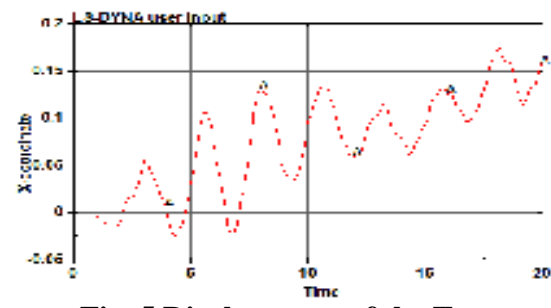

Fig. 5 Displacement of the Top Under Frequent Earthquake

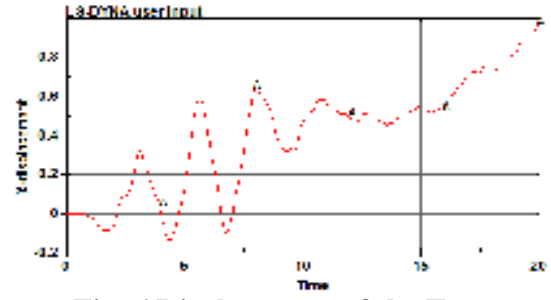

Fig. 6 Displacement of the Top under Rare Earthquake

Collapse Analysis under Huge Earthquake. Adjust the peak of seismic wave to $4 \mathrm{~m} / \mathrm{s}^{2}$, its seismic intensity is equivalent to seismic intensity VIII according to the Chinses Seismic Design Code, the collapse reaction of the calculated structure are shown in Fig. 7. Under the huge earthquake action, damage first occur in the bottom edge middle column of the long side, its destroyed time is in the 8.3 second. The second destroyed column is the adjacent bottom edge column of long side, its destroyed time is in the 9.4 second. The third destroyed colume also is the bottom edge middle column of long side, its destroyed time is in the 9.8 second. The failure of bottom columns extends from outside to inside, and most of the bottom structure columns are destroyed before the collapse of structure. At last, because the bottom bearing capacity of the structure is insufficient, the structure appear collapse. 


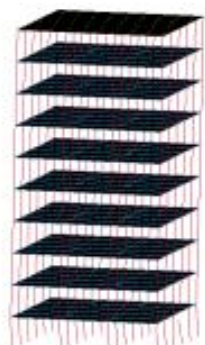

(a)

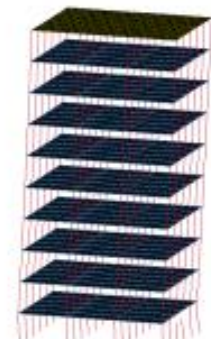

(b)

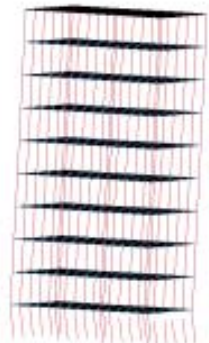

(c)

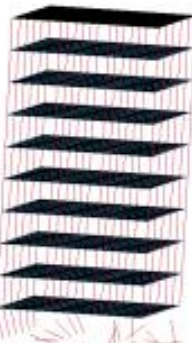

(d)

(a) $\mathrm{t}=9.2 \mathrm{~s}$; (b) $\mathrm{t}=9.4 \mathrm{~s}$; (c) $\mathrm{t}=9.9 \mathrm{~s}$; (d) $\mathrm{t}=19.8 \mathrm{~s}$

Fig. 7 The Deformation Diagram of Structure Collapse

\section{Conclusions}

Refer to the specifications, based on the main factors of the anti-earthquake collapse of RC frame structures, the IDA method is used to analyze the anti-seismic collapse of the RC frame structure. The time-history analysis results show with the increasing of seismic action, the seismic response of the structure becomes more and more obvious. Under the frequent earthquake and rare earthquake, the collapse of the structure does not appear, but the displacement of the top structure increased significantly under rare earthquake. Under the action of earthquake intensity $4 \mathrm{~m} / \mathrm{s}^{2}$, because the failure of the structure bottom columns cause collapse of the overall structure. Because the one of main reasons of structural collapse is the failure of the bottom columns, the energy dissipation capacity of the whole structure can not be fully exerted. It is suggested that on the study of RC frame structure anti-seismic collapse, the design of key parts and key components should be strengthenedn to improve the anti-collapse ability of the whole structure.

\section{Acknowledgements}

The research work was financially supported by the Key Scientific Research Project of Hubei Provincial Department of Education (D20133003).

\section{References}

[1]Lu Xingzheng, Ye Lieping, Miao Zhiwei: Elasto-plastic analysis of building against earthquake. edited by China Building Industry Press. (2009)

[2] Han Xiaolei, Cui Jidong, Ji Jing, Liu Wangjun, Shen Xuelong. Component-performance-based collapse resistant capacity evaluation of reinforced concrete frame structures under strong earthquake actions[J]. Journal of Building Stuctures, Vol. 36, p.27-34. (Dec. 2015)

[3] Lu Xingzheng, Tang Daiyuan, Ye Lieping, Shi Wei. Study on the seismic collapse resistance of $R C$ frame structures with equal spans in zones with seismic intensity. Journal of Earthquake Engineering and Engineering Vibration, Vol. 31, p.13-20. (Oct. 2011)

[4] Yang Feng, Wang Shengli, Dong Shuqing, Yang Xina. Study on Seismic Collapse Performance of the RC Frame Sturcture[J]. Electric Prower Survey \& Design, No. 4, p.27-29. (Aug. 2014)

[5] Yi Weijian, He Qingfeng, Xiao Yan. Collapse Performance of RC Frame Structure[J]. Journal of Building Structures, Vol. 28, p.104-117. (Oct. 2007) 